\title{
BASIC DESIGN OF A NEW MULTICOMPONENT STANDARD MACHINE AND PROPOSAL FOR A DEFINITION OF THE NOMINAL LOADS
}

\author{
D. Schwind ${ }^{1}$, M. Eller ${ }^{2}$, U. Kolwinski ${ }^{3}$ \\ GTM Testing and Metrology GmbH, Bickenbach, Germany \\ ${ }^{1}$ daniel.schwind@gtm-gmbh.com, ${ }^{2}$ martin.eller@gtm-gmbh.com, ${ }^{3}$ ulrich.kolwinski@gtm-gmbh.com
}

\begin{abstract}
:
The increasing demand in industry for calibrated multicomponent measuring, especially with mixed loads, supports the necessary development for the next level of Multicomponent Standard Machines. Our next step is a flexible machine, which ensures an automatic force and moment generation for realistic load situations. The multicomponent measuring in realistic load situations improves test results, assures comparability to application and reduces time expenses in calibration. This paper deals with definition of the capacity of the main components of the new machine type and its possibilities for realistic applications.
\end{abstract}

Keywords: multicomponent calibration; multicomponent standard machine; hexapod; Stewart platform

\section{INTRODUCTION}

Multicomponent measurements are getting more and more important in industrial applications [1]. Many applications are integrated in numerous test benches in automotive, aviation, aerospace, railway and robotic industries. The customers need application-oriented calibrations of their multicomponent force transducers. A lot of applications include eccentric loads, levers and introduce mixed loads in testing. It is necessary to perform practice-oriented, flexible and traceable multicomponent calibrations taking into account the vector properties and using self-developed procedures [2]. Therefore, GTM decided to develop a new fully automatic Multicomponent Standard Machine, see Figure 1.

\section{DESCRIPTION}

The Multicomponent Standard Machine consists of a machine frame, including three columns, fixed in an upper crosshead and a lower crosshead. A 3-point spindle drive allows an adjustment of the working unit in vertical direction.
The machine has a weight of approximately $20 \mathrm{t}$ and a construction height of $4.5 \mathrm{~m}$ up to $6.5 \mathrm{~m}$, if the working unit is adjusted in the upper end position.

The force and moment generation is represented by a hexapod drive unit [3], installed at the working unit. The load measurement is represented by a traceable Multicomponent Measuring Platform. It is installed in the bottom of the machine frame. It allows measuring the force and moments in all six degrees of freedom (DOF). The test space has a usable base area of $1.5 \mathrm{~m} \times 1.5 \mathrm{~m}$ and a height of up to $2 \mathrm{~m}$.

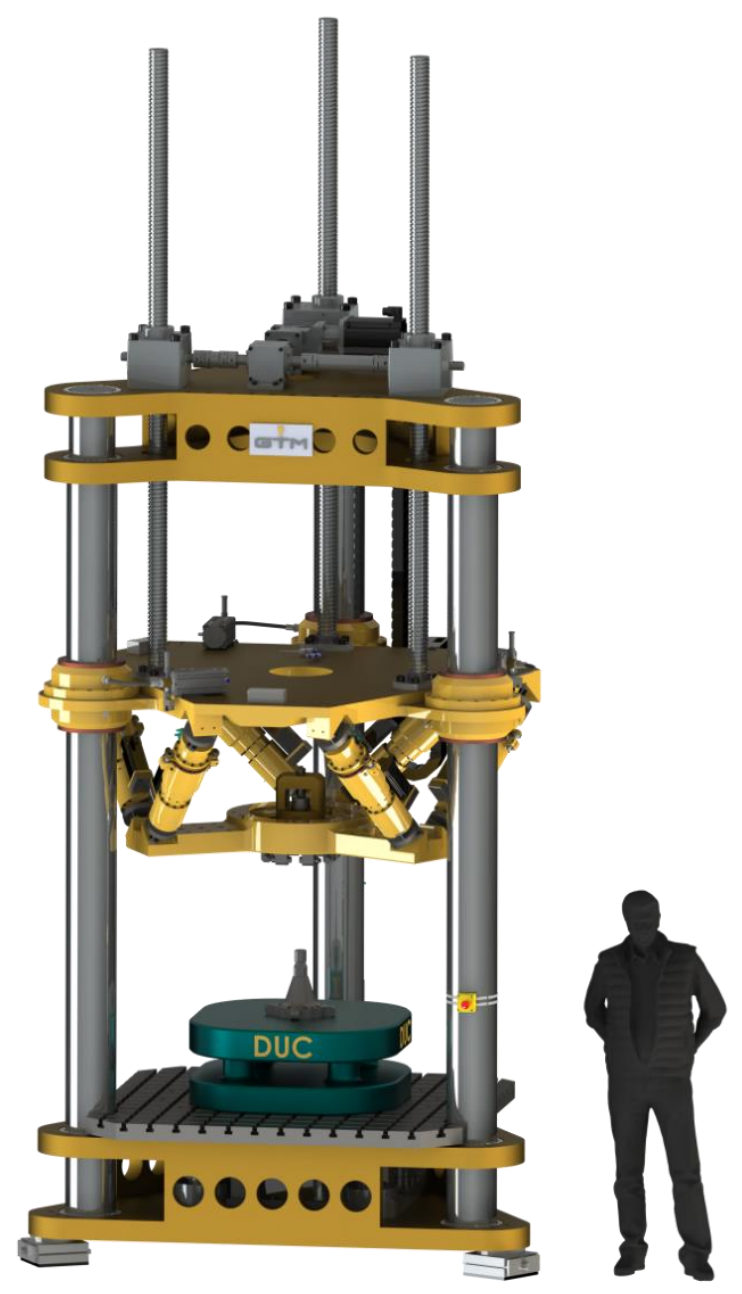

Figure 1: Multicomponent Standard Machine 


\section{CALIBRATION EQUPMENT}

\subsection{Multicomponent Measurement Platform}

The Reference System is able to measure the mixed loads simultaneously, see Figure 2. The device under calibration (DUC), e.g. a multicomponent transducer, or any multicomponent measuring system, is fixed on the upper plate of the Reference System without backlash through a fixing plate. Calibration results have to be transformed from the coordinate system of the measuring platform to the coordinate system of the DUC. It is important to know the geometric properties of the Reference System as well as of the DUC, to precisely determine the introduced forces and moments.

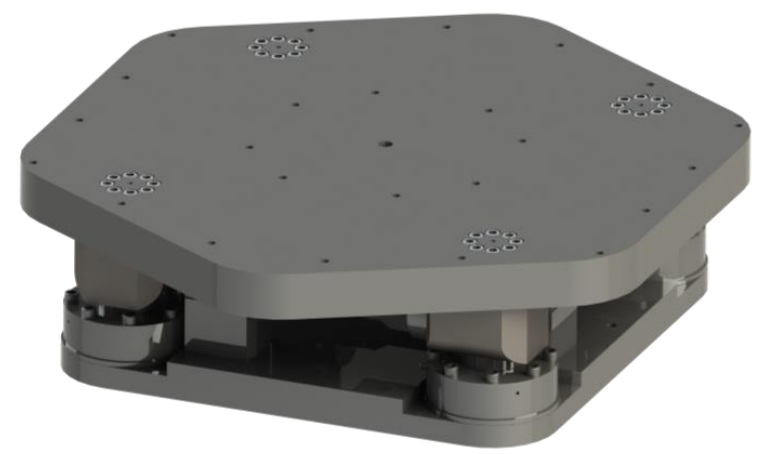

Figure 2: Multicomponent Reference System

\subsection{Hexapod}

The loads are generated by a GTM-developed hexapod, see Figure 3. It consists of six podes powered by electromechanical actuators. The podes and joints are working without backlash. This unit is able to generate mixed loads. The main adapter which can be disassembled is mounted in the centre of the movable platform of the hexapod.

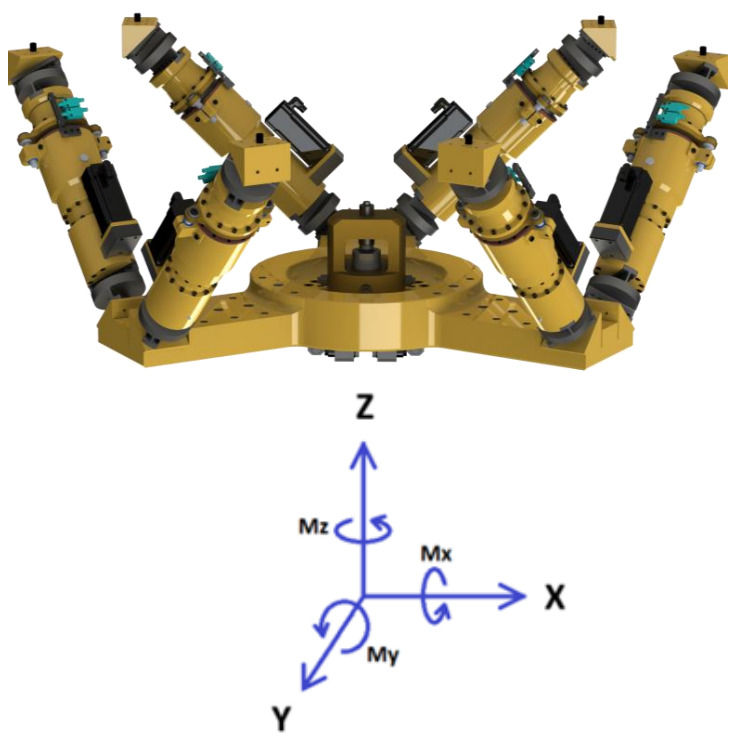

Figure 3: Hexapod

\section{MOUNTING AND CALIBRATION PROCEDURE}

The DUC is mounted on the fixing plate, which is bounded with the upper plate of the Multicomponent Reference System. Subsequently the hexapod drive unit moves down until the mounting position is reached. An exact adjustment is achieved through an additional manual control and an adapter. The GTM-developed adapter insures the connection between the DUC and the movable platform of the hexapod unit without backlash. The force introduction point is selectable for a realistic measurement with an automatically and a manual mode.

\section{REALISTIC FORCE AND MOMENT INTRODUCTION}

There are requirements to calibrate multicomponent force transducers in the same way they are used in real life. A realistic calibration ensured by additional components may be levers to define the introduction point in an eccentric way. Therefore, it is possible to calibrate a DUC in the same way as it is used by the customer. Further this simulation increases the accuracy and plausibility of the values of the measurement. An important property represents the zero-point passage during the measurement. In addition to this, it does not require to turn and remount the DUC during the process.

The levers can be mounted on the movable hexapod plate in different eccentric positions, see Figure 4 . The force transmission is insured by an additional adapter, which can be mounted eccentrically at the movable hexapod plate. The eccentricity ranges from $0 \mathrm{~mm}$ to $700 \mathrm{~mm}$.

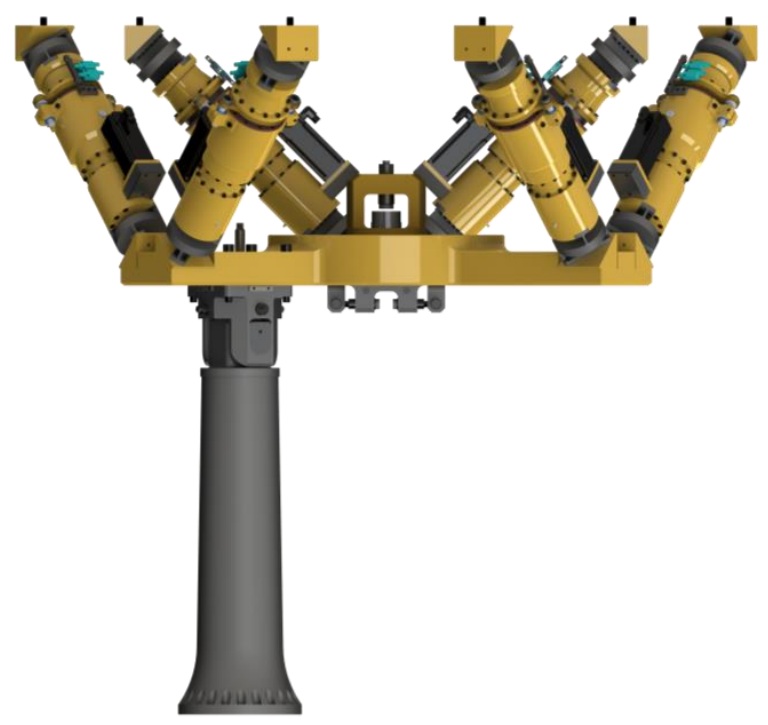

Figure 4: Hexapod with an eccentric mounted lever 
Both adapters are constructed from two parts. The first component is fixed in the hexapod drive unit. If necessary, it can be exchanged. The corresponding component is mounted on the DUC. During calibration the two components are connected to transmit the hexapod generated loads to the DUC.

\section{NOMINAL LOADS OF THE CALIBRATION EQUIPMENT}

The hexapod-generated loads can be measured by two additional Multicomponent Reference Systems (MRS) optionally mounted on the main Reference System hidden in the bottom. The advantage here is an optimization of the measuring accuracy for lower loads.

Table 1: Force and moment values

\begin{tabular}{|c|c|c|c|c|c|c|}
\hline $\begin{array}{c}\text { Maximum } \\
\text { Load }\end{array}$ & $\boldsymbol{F}_{\mathbf{x}}$ & $\boldsymbol{F}_{\mathbf{y}}$ & $\boldsymbol{F}_{\mathbf{z}}$ & $\boldsymbol{M}_{\mathbf{x}}$ & $\boldsymbol{M}_{\mathbf{y}}$ & $\boldsymbol{M}_{\mathbf{z}}$ \\
\cline { 2 - 7 } & $\mathbf{k N}$ & $\mathbf{k N}$ & $\mathbf{k N}$ & $\mathbf{k N} \cdot \mathbf{m}$ & $\mathbf{k N} \cdot \mathbf{m}$ & $\mathbf{k N} \cdot \mathbf{m}$ \\
\hline $\begin{array}{c}\text { Hexapod } \\
\text { drive unit } \\
\text { (centre) }\end{array}$ & 200 & 200 & 500 & 50 & 50 & 50 \\
\hline MRS 1 & 200 & 200 & 500 & 160 & 160 & 160 \\
\hline MRS 2 & 40 & 40 & 70 & 10 & 10 & 10 \\
\hline MRS 3 & 4 & 4 & 10 & 1.25 & 1.25 & 1.25 \\
\hline
\end{tabular}

\section{DEFINING THE CAPACITY OF A MULTICOMPONENT STANDARD MACHINE}

At the beginning of a new era of Multicomponent Standard Machines, we should determine how to define the nominal loads. The specification must give a clear statement about the measuring range and the measurement uncertainty, as it is necessary to declare it in the scope of an accreditation certificate or in CMC (Calibration and Measurement Capabilities) uncertainty statements e.g. of BIPM.

Additionally the technical data about the capacity must be transparent for the customer, if the Multicomponent Standard Machine is suitable for a special DUC. It must be apparent if the machine meets the calibration requirements. Based on the following definition, it is possible to describe the capacity of this machine type.

\subsection{Specification of Force Generation by the Drive Unit}

An important fact of the Multicomponent Standard Machine described in this paper is that the Multicomponent Reference System is able to handle much higher moment as the drive unit is able to introduce directly without using a lever. Therefore the capacity of the Multicomponent Standard Machine should be specified by the possible loads of the drive unit.

\subsection{Specification by Maximum Single Forces and Moments}

Possible definitions are dealing with mixed-load or single load specification. The disadvantage of a mixed-load specification is the missing information about the maximum forces and moments the Multicomponent Standard Machine is able to handle.

The most useful definition is to give the maximum single load specification, generated in the centre of the hexapod. In this definition the information about the possible maximum capacity is given.

In addition to this, it is important to know the eccentric possible load introduction points relating to their maximum single-load properties.

\section{CONCLUSION}

A new GTM-developed Multicomponent Standard Machine is built up in 2020. It allows measuring mixed loads simultaneously. An advantageous feature represents the zero-point passage and a realistic force introduction. The very promising option to define the machine capacity is to specify the maximum loads acting at the introduction point.

\section{REFERENCES}

[1] D. Schwind, "Multicomponent-transducers: definition, construction types and calibration considerations", Proc. IMEKO TC3, TC5 and TC22 Conference, Pattaya, Thailand, $22-25$ November 2010. Online [accessed 20200818]:

https://www.imeko.org/publications/tc32010/IMEKO-TC3-2010-006.pdf

[2] D. Schwind, H. Raabe, "A new calibration procedure for multicomponent transducers", Proc. XX IMEKO World Congress, Busan, Republic of Korea, 9-14 September 2012. Online [accessed 20200818]:

https://www.imeko.org/publications/wc2012/IMEKO-WC-2012-TC3-O25.pdf

[3] D. Röske, "Metrological characterization of a hexapod for multi-component calibration device", Proc. XVII IMEKO World Congress, Dubrovnik, Croatia, 22-27 June 2003. Online [accessed 20200818]:

https://www.imeko.org/publications/wc2003/PWC-2003-TC3-021.pdf 